\title{
d-Vision: Seeking Excellence Through A Hands On Engineering Multi Discipline Global Internship Program
}

Gavin Suss, Keter Plastic Group, Israel

\begin{abstract}
The question is, "What can vision do?" (Fritz, 1989) rather than "What is vision?" Keter's Chairman, Mr. Sami Sagol's vision is to establish an internship program that will strengthen the competitive edge of the Israeli industry, within the international arena. The program will set new standards of excellence for product development, engineering, technology and design. Mr. Sagol's vision of excellence, in the internship program, has commenced in a process of changing Keter from a conservative industry to a learning organization, which promotes innovation, excellence, and knowledge. His vision has changed Keter.
\end{abstract}

\section{INTRODUCTION}

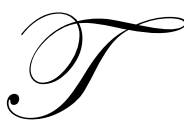

he Keter Group (www.keter.com) is one of the world's leading manufacturer of plastic consumer products and a global force in the do-it-yourself (DIY) household and garden furniture markets. Keter plastics was founded in 1948 by the late Joseph Sagol, one of Israel's leading industrial pioneers. With over 61 years of experience Keter Group operates 28 factories in Israel, Europe and the United States, manufacturing a wide range of products, including, outdoor storage units, shelving systems, utility cabinets, tool boxes and storage products, as well as products for young children, which are sold in over 90 countries worldwide. In Israel, Keter Plastics operates its own chain of retail outlets.

Several years ago the owner and chairman of the group Sami Sagol established a global design internship program named d-Vision (www.d-vision.co.il). It is known that most organizations prefer to run their own in-house courses tailored to their needs and addressing their issues (Sloane, 2009) yet such a program like the one presented here is unique as its major objective is to promote excellence, and not necessarily employ the interns of the program when they graduate.

d-Vision is an internship program for Product Development, Engineering and Industrial Design. The main target of the project is to foster the next generation of outstanding industrial designers and engineers in Israel. The objective of this program, as expressed by the initiator of the program, is to strengthen the competitive edge of the Israeli industry in the international arena by setting new standards of excellence for product development, engineering, technology and design. The program's strategic premise is that success in the global markets requires talented product designers and engineers who have been exposed to both valuable hands on experience and state-ofthe-art professional know-how. $\mathrm{d}$-Vision is a unique, bold pioneering program and the interns enlisted in this program commit to 2 years of intensive training and work including individual guidance and support throughout the program.

Following the success of design interns participating in the d-Vision program, during 2008, the program recruited Plastic and Industrial Engineers to the program.

Engineers play a critical role in driving the global economy. Industry needs highly educated, corporate engineers to ensure innovation and technological leadership. Industry needs engineers who strive for the best by achieving high-performance, in a highly competitive global market. Industry requirs a new breed of engineers: 
technically broad, able to work and cooperate in multi discipline teams (with designers) commercially savvy, and globally adept.

This paper presents the Multi Discipline Engineering Global Internship Program and its unique characteristics.

\section{THE ENGINEERING PROGRAM OF D-VISION:}

Rodrigues (2001) talks about the information literacy expectations of engineers in the corporate world, and the shortcomings of engineers in this area. Because engineers in the corporate world are expected to find specific data, and also be able to locate and create patents and other intellectual property, graduating engineering students benefit greatly from a basic knowledge and engineers should know about the design and content of technical databases, as-well-as non-technical resources that provide information about competitors, suppliers, products, and management techniques. The reality seems to be that many engineers do not take advantage of the information resources available to them and commence employment based on their academic knowledge which, simply now days is not enough.

The fundamental target of the program is to develop and nurture excellent engineers that will have the knowledge and tools to cope with the future challenges of plastic manufacturing while supplying innovative technology solutions in a changing competitive world. Likewise, in a changing world, human capital has become even more cardinal and there is a growing recognition that more and more of the market value of firms rests on their human capital (Lawler \& Worley, 2006). If this is the case investing in human capital will have a dramatic return to the investor. Therefore, this program addresses the critical needs of developing an engineering workforce that is prepared to tackle the immense number of global challenges of the 21 st century Corporation.

Engineer students have a heavy workload (Hill \& Woodall, 1999) and this creates stress and pressure for the young graduates and interns. The environment of an engineer student in the academy is different from other students, as the graduated are accepted immediately after they complete their degree, the program takes in to consideration this factor and is built to enable a quick and convenient culture for the interns while emphasizing the need to adapt changes to promote excellence.

Schon (1973) provided a theoretical framework linking the experience of living in a situation of an increasing change with the need for learning.

The loss of the stable state means that our society and all of its institutions are in continuous processes of transformation. We cannot expect new stable states that will endure for our own lifetimes.

We must learn to understand, guide, influence and manage these transformations. We must make the capacity for undertaking them integral to ourselves and to our institutions. In other words, we need to become adept at learning. We must become able not only to transform our institutions, in response to changing situations and requirements; we must invent and develop institutions which are 'learning systems', that is to say, systems capable of bringing about their own continuing transformation. (Schon 1973: 28).

The spirit of The Engineering Program in Keter is influenced from Schons approach, the program promotes the context of change and transformation in the syllabus and in the hands on work the interns are required to do. The program emphasis the need to require knowledge and develop a tool box that will enable engagement in organizational changes.

Learning organizations [are] organizations where people continually expand their capacity to create the results they truly desire, where new and expansive patterns of thinking are nurtured, where collective aspiration is set free, and where people are continually learning to see the whole together. (Senge 1990: 3)

The Learning Company is a vision of what might be possible. It is not brought about simply by training individuals; it can only happen as a result of learning at the whole organization level. A Learning Company is an 
organization that facilitates the learning of all its members and continuously transforms itself. (Pedler et. al. 1991: 1). (This is not the place to elaborate but since the engineers were recruited to the program several internal managerial courses have opened in Keter for managers and employees, and are part of the learning organization environment culture of the group).

Learning organizations are characterized by total employee involvement in a process of collaboratively conducted and collectively accountable change directed towards shared values or principles. (Watkins and Marsick 1992: 118). In traditional firms, managers are looking to cut deadwood (which should always bring to mind the question, did you hire them dead, or did you kill them"?). In b2change firms (like Keter) managers are seeking to see if talent is still aligned with the changing needs of the firm (Lawler \& Worley, 2006) and by doing so ensure a new innovative talent generation of engineers updated by the recent technology and managing methods.

As stated the duration of the program is two years and its syllabus includes the following four parts and seeks to define areas of knowledge, skills and attitudes.

\section{A SCHOLARSHIP TOWARDS A MA DEGREE}

Engineering based organizations should collaborate more across the borders; they should work to strengthen the dialogue between professional practice and academia; they should help define and monitor global engineering qualifications. This being the case all interns are required to begin their Masters degree (they will receive a full scholarship for two years) in a leading academic institution in Israel. (The masters programs are usually one day a week and/or on Friday mornings). Currently, the interns are studying towards a MBA degree, but some have chosen to master in Logistics and Plastics. In the future we hope to send the interns to a leading University in the United States for a semester or a professional course.

\section{HANDS ON EXPERIENCE IN THE COMPANY}

The interns work in Keter's companies in Israel 3-4 days a week - developing hands-on experience and collaborating with senior employees, managers and designers within the companies. This is a very important part of the program as it exposes the interns to the technology, culture and products of the company, creating multi discipline teams of engineers and designers working together on projects. Each intern will work on 1-3 projects at a time in 1-2 different companies (locations) - yet exposing them to multi cultures and people in the group.

One of the companies is the headquarter of the chairman where the development department is located with the designers of the d-Vision mother program The interns at different stages of their work will be part of teams with the design interns and work together on multi discipline projects including design, martial's, process and development.

\section{PERSONAL AND PROFESSIONAL DEVELOPMENT COURSES:}

Personal and professional development courses are conducted once a week and include a set of courses on several topics that are not taught in the academic world but are very important in the industrial world and culture of Keter - for example: Meeting failure or better known the success of failure (Wayfarer, 1913), leading change, team work, blue ocean strategy, software programs, accountability, business English, strategy, leadership and more. These sessions are conducted in a small group enabling the management to get closer to the interns or better said by Scolese (2007) engineering excellence is about more than risk reduction, though-again, it is about people. (This part includes participating in local and international conferences).

\section{COACHING AND INTERNAL COURSES TOWARDS PERSONAL EMPOWERMENT}

An internal enrichment set of courses related to management, conducting negotiations, emotional intelligence, presentation skills and more are taught on Friday's (most companies in Israel do not work on Fridays). This part and all meetings are conducted in English and the head of the program leads this process and personally coaches the young interns. 
Likewise, meetings with executives of the group are conducted on a monthly basis, exposing the interns to the leaders and their vision of the group on the one hand and enabling them to learn the history and legacy of the group, which is of great value

The practical part of the program enables the interns to work in the different plants in Israel, and get exposed to the process of plastic manufacturing, and conduct daily sessions with leading managers and employees of the group.

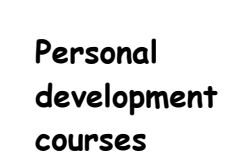

courses

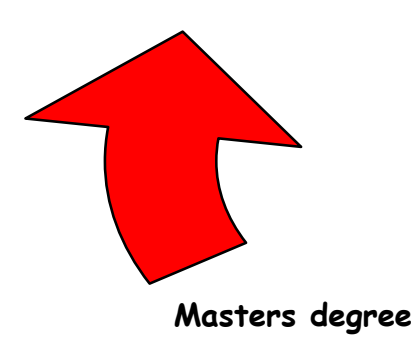

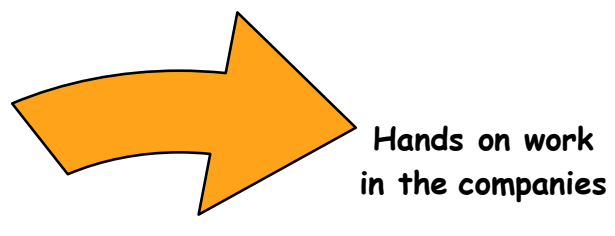

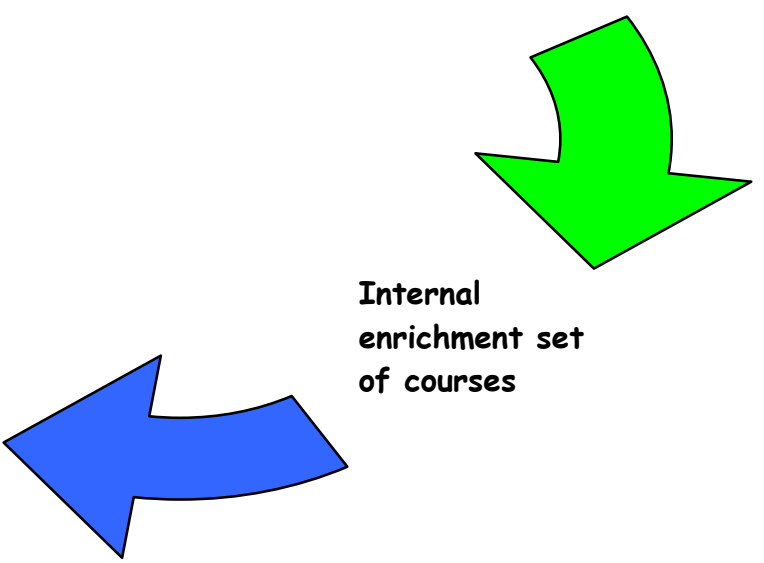

The above diagram is part of a wider concept believing that the best way to bring up an excellent engineer is button - up namely, by enabling the new recruited interns to work themselves up from the manufacturing floor to a managerial position, BUT the process will not be traditional where the new employee (intern) works a full week. The diagram is unique and promises to expose the interns to the word of engineering and simultaneously breed them with knowledge and content related to the work of engineering and management. As mentioned above the process includes coaching the young interns and empowering them with personal development courses that will set the seeds in the company that when the interns become mangers themselves in or outside Keter. The basic knowledge they received during the program will be the platform for them in their developing career towards management in learning organizations of excellence.

According to Sandra Kerka (1995) most conceptualizations of the learning organizations seem to work on the assumption that 'learning is valuable, continuous, and most effective when shared and that every experience is an opportunity to learn. That is the case here consistent learning with working, the symbioses of the two elements has created a formal and informal interaction in the group where interns collaborate in teams with senior employees and conduct presentations to mangers. This interaction has created a dialogue among the interns and managers and a vast interest in the program and its content, Senge (1994) finds that "teams, not individuals, are the fundamental learning unit in modern organizations."

A Library and software has been purchased for the interns creating an environment of reading and research, protocols and updates among the interns. 


\section{CONCLUSION}

How do we achieve engineering excellence? Scolese (2007) answers this question regarding developing engineering excellence in NASA, "I see it in terms of four guiding principles: clearly documented policies and procedures, effective training and development, engineering rigor, and open communication. All are necessary to enable people to perform at their best in the unique context of NASA, a high-reliability organization that builds oneof-a-kind systems".

The program presented here implements these guiding principles emphasizing the need for effective training, development and open communication with the interns. The program asks the interns to think like engineers and to solve a series of challenges using the engineering design process as in Keter. The polices, processes, and procedures help the participants in the program work collaboratively namely allowing them to complete tasks effectively in a repeatable manner (Scolese, 2007).

Organizations with the best chance to succeed and thrive in the future are learning organizations (Senge, 1994), if this is the case it has become cardinal and in some cases a matter of life or death for organizations to conduct change and engage in a culture of learning.

It could be argued that the notion of the learning organization provides managers and others with a picture of how things could be within an organization. Along the way, writers like Peter Senge (1994) introduce a number of interesting dimensions that could be personally developmental, and that could increase organizational effectiveness - especially where the enterprise is firmly rooted in the 'knowledge economy'.

Investment in the Human capital is fundamental to create an excellent organization and a learning one. The program here is based on Schon's approach (1973) which believes that we must invent and develop institutions which are 'learning systems', that is to say, systems capable of bringing about their own continuing transformation in coloration with the new developments out of the company. This process is better achieved by recruiting young excellent graduates (in this case engineers and designers) and developing them academically and professional in a world of learning, technology and knowledge emphasizing the personal development of the interns in multi discipline teams in the organizational culture.

Managing such a program in a 61 year old organization is not an easy task, not from the cultural aspect and not from the organizational one, yet, the change was required to meet the challenges of the market and promote excellence in the fields of design and engineering, Keter has embraced change and excellence, whereas, organizations that seek stability cannot learn to orchestrate change. Similarly, organizations that do not reflect on the change experience will not learn as much as they should (Lawler \& Worley, 2006).

Engineering excellence intends to be pivotal to global economic growth, so every industry needs engineers equipped to achieve top results, to function as primary catalysts of management and outstanding cultural achievement in a changing world, Keter's Engineering Multi Discipline Global Internship Program is on a path towards this challenge and simultaneously developed a climate of a learning organization in Keter

Let me conclude with a quotation of Jack Welch "An organization's ability to learn, and translate that learning into action rapidly, is the ultimate competitive advantage". So through the $\mathrm{d}$-Vision program we hope to meet this objective successfully.

The question is, "What can vision do?" (Fritz, 1989) rather than "What is vision?"- In this case Vision has changed Keter and created a culture of innovation, learning, knowledge and excellence.

\section{AUTHOR INFORMATION}

Gavin Suss completed a MA with Honors in Education Management and a PhD in Education from the Tel Aviv University. Served as the Academic Director of the prestigious Shenkar College of Engineering and Design for 5 years and is currently Head of the Engineering Internship program in Keter Plastic Group. Likewise, he serves as a 
Director on behalf of the State of Israel in the Jewish Archives and served as General Director of VARAM the high committee of the public colleges in Israel. Suss lectures in Israel, abroad and has published several papers in international and local journals.

\section{BIBLIOGRAPHY}

1. Argyris, C., \& Schön, D. (1978) Organizational learning: A Theory of Action Perspective, Reading, Mass: Addison Wesley.

2. Fritz, R. (1989) The Path of Least Resistance: Learning to Become the Creative Force in Your Own Life Fawcett.

3. Hill, C.H and Woodall, L.B. (1999) Developing Information Literacy in First Year Engineering students , $11^{\text {th }}$ annual conference and convention Adelaide, Australia

4. Kerka, S. (1995) The Learning Organization: Myths and Realities. Eric Clearinghouse, http://www.cete.org/acve/docgen.asp?tbl=archive\&ID=A028.

5. Lawler,E \& Worley. (2006) Built to Change: How to achieve sustained organizational effectiveness. Jossey - Bass.

6. Pedler, M., Burgoyne, J. and Boydell, T. $(1991,1996)$ The Learning Company. A Strategy for Sustainable Development, London: McGraw-Hill.

7. Rodrigues, R.J. (2001) Industry Expectations of the New Engineer. Engineering Libraries: Building Collections and Delivering Services 19(3/4): 179-188.

8. Scolese, C (2007) Developing engineering excellence for programs and projects at NASA. Ask Magazine (Policy).

9. Senge, P. et. al. (1994) The Fifth Discipline. Strategies and Tools for Building a Learning Organization. Fieldbook.

10. Sloane, P (2009) The Innovative Leader. How to Inspire your Team and Drive Creativity. Kogan Page.

11. Wayfarer, A (1913) The Success of Failure. Tapman Publishing Company.

12. Watkins, K. and Marsick, V. (1992) Building the Learning Organization: a New Role for Human Resource Developers, Studies in Continuing Education 14(2): 115-29.

\section{APPENDIX}

Table 1: Interns in program, employed after the program and drop out after employment.

\begin{tabular}{|l|c|c|c|c|}
\hline & Interns & $\begin{array}{c}\text { Employed after the } \\
\text { program in Keter }\end{array}$ & $\begin{array}{c}\text { Drop out working in } \\
\text { Keter }\end{array}$ & Remarks \\
\hline First year & 16 & 10 & 3 & \\
\hline Second year & 8 & 3 & 0 & \\
\hline Third year & 15 & 9 & 0 & 2 Engineers \\
\hline Fourth year & 14 & Still in program & 0 & 5 Engineers \\
\hline Fifth year & 18 & Still in program & 3 & Engineers \\
\hline
\end{tabular}

Currently the fourth and fifth years are in the program.

1. $56 \%$ of all interns were employed in Keter after completing the program.

2. $13 \%$ of the interns that were employed left the company.

The interns are not required to sign a contract obligating them to work in Keter when completing the program.

The engineering program URL: (http://www.d-vision.co.il/152103): 